\title{
Use of anorectal ultrasounds in perianal Crohn's disease: consistency with clinical data
}

\author{
F. de la Portilla, E. León-Jiménez¹, N. Cisneros, R. Rada, B. Flikier, J. Vega and V. Hugo Maldonado \\ Unit of Coloproctology. Service of General and Gastrointestinal Surgery. Hospital Juan Ramón Jiménez. Huelva, Spain. \\ ${ }^{\prime}$ Service of Internal Medicine. Hospital de Valme. Seville, Spain
}

\begin{abstract}
Background: anorectal ultrasonography (ARU) is a simple technique, and its diagnostic value for anorectal diseases either in conventional subjects or in patients with Crohn's disease (CD) is insufficiently reported. The objective of this study is to evaluate the use of ARU, its consistency with clinical orientation, and its ability to provide relevant information for patients with bowel CD and perianal involvement.

Methods: thirty ARUs were performed for 24 patients (17 male, mean age 35,7 years; range 19-59 years) with diagnosed $\mathrm{CD}$ (bowel and anorectal involvement). The reason to perform an ARU was to evaluate an anal fistula (15 patients, 50\%), potential abscesses (9 patients, 30\%), and fecal incontinence (2 patients, $6,6 \%$ ), and for post-treatment monitoring purposes (4 patients, $13,3 \%)$.

Results: diagnostic orientation coincided for 14 patients $(46,6 \%)$. An abscess was found in eight patients $(26,6 \%)$, and five patients were clinically suspicious. The abscess was postanal in 3 patients. Fistulas were found in 17 patients (56,6\%), and 15 patients were clinically suspicious. Transsphincterian fistulas were observed in seven patients, and abscesses were associated with fistula in six patients. Transsphincteric defects were observed in 10 patients (four internal sphincters, one external sphincter, and five both) but only two patients suffered from incontinence. ARU provided data relevant to therapeutic approach in 19 patients $(63,3 \%)$.

Conclusions: ARU has provided very important data for the diagnosis and treatment of anorectal diseases. Based on this technique clinical decisions can be improved, which in some instances may prove critical.
\end{abstract}

Key words: Anorectal ultrasounds. Perianal. Crohn's disease. Treatment. Diagnosis.

Recibido: 24-03-06.

Aceptado: 20-06-06.

Correspondencia: Fernando de la Portilla. Unidad de Coloproctología. Servicio de Cirugía General y Aparato Digestivo. Hospital Juan Ramón Jiménez. Ronda Norte, s/n. 21005 Huelva. Fax: 9590167 84. e-mail: delaporti1la@ya.com de la Portilla F, León-Jiménez E, Cisneros N, Rada R, Flikier $B$, Vega J, Hugo Maldonado V. Use of anorectal ultrasounds in perianal Crohn's disease: consistency with clinical data. Rev Esp Enferm Dig 2006; 98: 747-754.

\section{INTRODUCTION}

Anorectal involvement in Crohn's disease (CD) has been reported to be present in $22-54 \%$ of all cases $(1,2)$. Anorectal affectation can occur simultaneously with lesions characteristic of bowel $\mathrm{CD}$, or it may constitute the first symptoms of disease in $8-16 \%$ of patients (3). Perianal disease occurs more frequently when CD involves the colon, and its incidence is lower when it affects the small bowel. Anorectal involvement can be present as mucosal ulcers, abscesses, and anal or perianal fistulas. In most cases $(62 \%)$ such lesions are painless and of slow growth (4), and may delay diagnosis and early effective treatment (5-11).

Physical examination, even under anesthesia, and other diagnostic tools are crucial for a proper evaluation of anorectal disease. Anorectal ultrasounds (ARU) is a simple, inexpensive, and well tolerated technique with a high diagnostic value for anorectal diseases both in conventional subjects and patients with $\mathrm{CD}$ when compared to other tools (12-17).

The objective of this study was to evaluate the use of ARU, its consistency with clinical orientation, and its ability to provide relevant data for patients with bowel $\mathrm{CD}$ and perianal involvement.

\section{MATERIALS AND METHODS}

The study included 17 male and 7 female patients with a mean age of 35,7 years (range 19-59). A total of 30 ARU procedures were performed from January 
2002 to 2005. An ARU was performed in 24 patients diagnosed with bowel CD or with clinical suspicion of anorectal involvement.

A B\&K ultrasound machine (model 2001) was used, with a rigid probe (model 1850) coupled with a $360^{\circ} 10$ $\mathrm{MHz}$ rotating transducer. Patients were positioned in left lateral decubitus without any prior bowel preparation for a mean of 8-min exploration (range 5-12 min). Images were printed, and occasionally video-recorded for reviewing.

The presence of typical perianal CD (PACD) lesions was evaluated mainly by abscesses and fistulas, and by the presence of sphincter defects. Hypoechogenic images of fistulas as provided by ARU were more evident with hydrogen peroxide instillation through the external fistula orifice. The image consisted of a high hyperechogenic area with many reverberances. Fistulas were classed under Parks' classification, a mandatory finding being the internal fistulous orifice. Ultrasound images showing abscesses also consisted of a hypoechogenic area with poorly-defined or slightly hyperechoic edges. This was done in association with fistula tract evaluation, as well as anatomical position (Fig. 1). Finally, the presence of a sphicterian lesion, either on the internal or external sphincter, was evaluated in all patients.

The most typical reason to order an ARU was to evaluate an anal fistula (15 patients, 50\%). Other reasons were: potential abscesses ( 9 patients, $30 \%$ ), fecal incontinence ( 2 patients, 6,6\%), and clinical control post-treatment (4 patients, $13,3 \%)$.

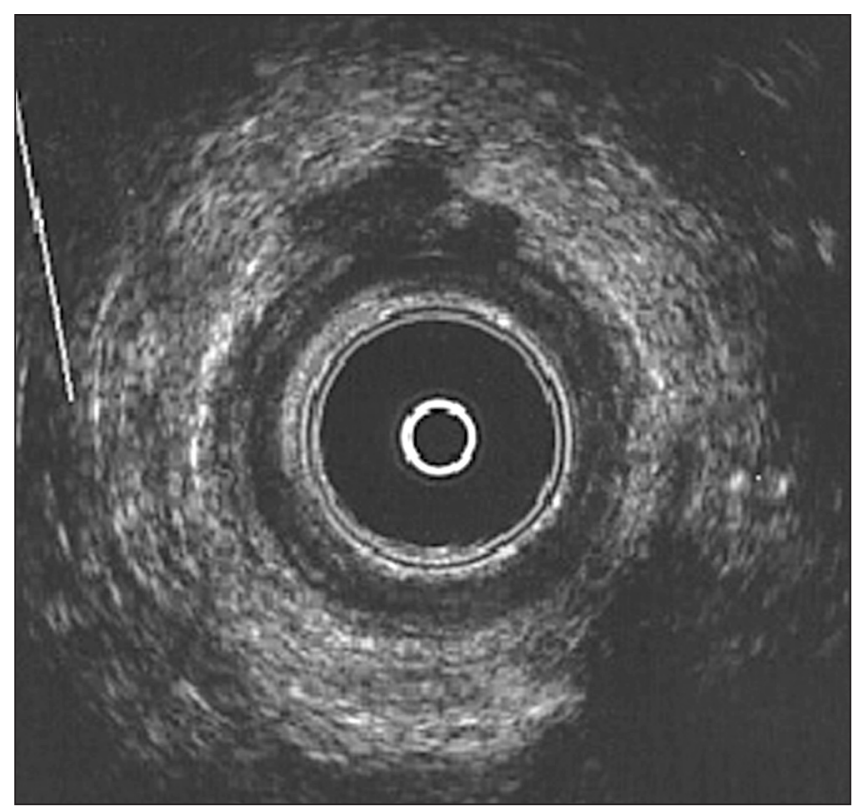

Fig. 1.- Anal ultrasound of a patient with PACD. An hypoechogenic irregular anterior image can be observed that seems consistent with an unsuspected abscess, as well as with an enlargement -probably inflammatory- of the internal anal sphincter (IAS).

Ecografía anal de un paciente con ECPA. Apreciamos una imagen hipoecoica irregular anterior que parece corresponder a un absceso no sospechado, así como un engrosamiento probablemente inflamatorio del esfínter anal interno.
ARU was coincidental with clinical suspicion when ultrasonograpic findings confirmed the reason for the test, and no extra information was available. When other findings were concurrent with the one clinically suspected no clinical-ultrasonographic coincidence was observed.

\section{RESULTS}

The clinical symptoms and ultrasound diagnoses for all studied patients are shown in table I. Diagnostic orientation coincided in 14 patients (46,6\%). An image consistent with an abscess was found in eight patients $(26,6 \%)$, and five of them were clinically suspected. Ultrasounds made it possible to define abscess location in the anal canal in all but one patient, and a postanal localization was observed in three patients.

Fistulas were found in 17 patients $(56,6 \%)$, and were clinically suspected in 15 patients. A fistula tract could be clearly defined in 10 patients, which made it possible to properly classify them. A transsphincterian fistula type was seen in seven patients. Abscesses were associated with a fistula in six patients.

Sphincterian defects were observed in 10 patients $(33,3 \%)$, but only two patients suffered from incontinence. Such defects were exclusive of the internal anal sphincter in four patients, of the external in one patient, and of both sphincters (internal and external) in five patients.

None of the four patients where an ultrasonogram had been performed to evaluate the evolution of disease showed any new findings that had not been clinically suspected before.

Lastly, three patients $(10 \%)$ had three pathologic events that were simultaneously associated (abscess, fistula, and sphincter defect).

Ultrasounds revealed relevant data for the therapeutic approach (antibiotics, immunosupressants, anti-tumor necrosis factor (anti-TNF) or surgery) in 19 patients $(63,3 \%)$.

\section{DISCUSSION}

The diagnosis and treatment of anorectal diseases in patients suffering from $C D$ is a medical challenge, mainly in the presence of anorectal fistulas. Symptoms and signs frequently reflect the presence of a more aggressive and severe underlying problem, such as severe proctitis associated with a fistulizing perianal disease (3). Alternatively, an early therapeutic attitude, especially in the case of abscesses, avoids unnecessary patient discomfort and may prevent further complications, including stenosis as caused by chronic abscesses with no proper drainage. 
Table I. Clinical and ultrasonographic data, as well as their concordance

\begin{tabular}{|c|c|c|c|c|c|}
\hline Case Number & Clinical suspicion & Abscess & $\begin{array}{l}\text { Ultrasound findings } \\
\text { Fistula }\end{array}$ & Sphincter defect & Concordance \\
\hline 1 & Abscess & No & No & No & No \\
\hline 2 & Fistula & No & Extraspihincteric & No & Yes \\
\hline 4 & Evolution control' & No & No & EAS & Yes \\
\hline 5 & Anal abscess & Intersphincteric & Intersphincteric & IAS & No \\
\hline 6 & Anal fistula & No & Intersphincteric & No & Yes \\
\hline 9 & Incontinence & No & No & No & No \\
\hline 10 & Anal fistula & No & No & IAS & No \\
\hline 11 & Anal fistula & No & Non classificable & IAS & No \\
\hline 12 & Anal fistula & Postanal & Transsphincteric & IAS & No \\
\hline 13 & Anal fistula & No & Transsphincteric & No & Yes \\
\hline 14 & Anal abscess & Non classificable & No & No & Yes \\
\hline 19 & Anal fistula & No & Transsphincteric & No & Yes \\
\hline 20 & Anal abscess & No & No & No & No \\
\hline 21 & Anal fistula & No & Non classificable & IAS/EAS & No \\
\hline 22 & Anal fistula & No & Non classificable & No & Yes \\
\hline 23 & Anal fistula & Postanal & Non classificable & IAS/EAS & No \\
\hline 24 & Anal fistula & No & Transsphincteric & No & Yes \\
\hline 25 & Anal fistula & Superficial & Transsphincteric & No & No \\
\hline 26 & Anal abscess & Intersphincteric & No & IAS/EAS & No \\
\hline 27 & Evolution control ${ }^{3}$ & No & No & No & Yes \\
\hline 28 & Anal abscess & No & No & No & No \\
\hline 29 & Anal fistula & No & Non classificable & No & Yes \\
\hline 30 & Evolution control ${ }^{4}$ & No & Non classificable & No & Yes \\
\hline
\end{tabular}

EAS: external anal sphincter; IAS: internal anal sphincter.

${ }^{1}$ Clinician suspected that only the already known sphincteric defect would be revealed.

${ }^{2}$ Clinician suspected a normal test after treatment was established.

${ }^{3}$ Clinician suspected a normal test after treatment was established.

${ }^{4} \mathrm{Clinician}$ suspected that patient only had a fistula refractory to treatment with antibiotics.

Despite the complex situations that can lead to perianal affectation in $\mathrm{CD}$, the clinical orientation based on the anamnesis and physical evaluation is often correct in most cases. However, in certain situations, such as non-filiated proctalgia and perianal sepsis, additional information as obtained by complementary techniques could be of great help to establish a more effective treatment strategy $(4,5)$.

Rectosigmoidoscopy reveals mucosal affectation, but cannot establish or evaluate lesions away from it. On the other hand, a barium enema can be useful for fistulas, but generally fortuitous findings usually define the real illness incorrectly $(6,7)$. Fistulography is another diagnostic method, but it is usually painful, uncomfortable, difficult to evaluate, and may cause local sepsis $(8,9)$.

Scanners (CT) can provide important information about perianal disease, and they are superior to ARU for detecting inflammatory perirectal changes. Both CT and ARU are equally effective for detecting abscesses. But ARU is superior for the detection and topographic delimitation of fistulas, and for the assessment of inflammatory infiltrates in pelvic muscles $(10,11)$.

Magnetic resonance imaging (MRI), either conventional or endoanal, is a non-ionizing and painless technique that allows the evaluation of perianal CD (mainly fistulas and abscesses) with a diagnostic certainty of 69 to $96 \%$. MRI is less effective than ARU and equivalent to a general exploration under anesthesia (12-14).

ARU is a quick and simple technique, requires no special preparation, and is well-tolerated by patients. It is inexpensive, and equipments are easy to transport, allowing exploration even at patient bedside (15). ARU is limited by pain or anal stenosis.

An endosonographic study performed with an echocolonoscope allows an in situ evaluation of the rectal mucosa and colon. It also allows the measurement of parietal width, and detects small abscesses or internal fistulas that may be undetected by simple colonoscopy $(16,17)$.

ARU is of great help in cases of fistulas that could not be clinically defined, and must be treated surgically 
by surgeons not used to this type of pathology. ARU provides valuable information on fistula type and tract, and thus helps in fistula resolution.

The use of ARU is reduced when trying to distinguish topography and to define the internal fistulous orifice, because of the complexity of fistulas in these patients $(16,18,19)$. However, this can be minimized by the instillation of hydrogen peroxide through the fistulous tract (14). In our study we could clearly distinguish the internal orifice and fistulous tract in over one half of cases, and detected elongations and hidden tracts, as well as evidence of hidden abscesses in $35 \%$ of explored fistulas.

The finding of a non-detected abscess in the clinical exploration by any image method is crucial for establishing treatment with anti-TNF and recommended use of a seton prior to the therapy. Based on these observations, ARU appears to be a highly sensitive technique (20). However, persisting pathologic images of activity not related with clinical evolution make evaluation of treatment response irrelevant (21).

The role of perianal ultrasounds and its ability to predict an effective response to treatment with infliximab has been recently evaluated. When associated with transvaginal ultrasounds in women, its diagnostic sensitivity improves in the evaluation of anorectal pathology $(20,21)$.

In our study we not only defined the location of unsuspected abscesses, but also the topography of some that were difficult to detect during physical exploration, as those in a postanal situation.

Undoubtedly, ARU is the main technique to evaluate the integrity of muscles in the anal canal. Most patients in our study had sphincteric lesions. While these lesions are clinically less evident, their detection is crucial for a possible surgical treatment (11-13). Interestingly, it was observed in our study that some patients had internal anal sphincter defects without having undergone prior surgeries.

In our study nearly $47 \%$ of ultrasound explorations coincided with the previous clinically suspected diagnosis. However, ARU revealed important information in over $60 \%$ of patients, and thus enabled a definitive treatment. ARU also provided interesting hints, such as the presence of sphincteric defects and abscesses associated with the clinical suspicion that led to ultrasonography. We should point out that a combination of good clinical exploration, ARU, and eventually MRI dramatically increases diagnostic yield in these patients (22).

In conclusion, ARU provided very important data for the diagnosis and treatment of patients with anorectal diseases, and it is strongly suggested that it should be performed after physical examination and colonoscopy. Therefore, clinical decisions may be improved based on this technique, which in certain cases can become essential, such as in patients with anal fistula or abscess suspicion, or to evaluate sphincters for a potential surgical approach.

\section{ACKNOWLEDGEMENTS}

The authors thank Mrs. Aguilar-Alba for her assistance.

\section{REFERENCES}

1. Willians DR, Coller JA, Corman ML, Nugent FW, Veidenheimer MC. Anal complications in Crohn's disease. Dis Colon Rectum 1981; 24: 22-4.

2. McClane SJ, Rombeau JL. Anorectal Crohn's disease. Surg Clin North Am 2001; 81: 169-83.

3. Rankin GB, Watts HD, Melnyk CS, Kelley ML Jr. National cooperative Crohn's disease study extraintestinal manifestations and perianal complications. Gastroenterology 1979; 77: 914-20.

4. Keighley MR, Allan RN. Current status and influence of operation on perianal Crohn's disease. Int J Colorect Dis 1986; 1: 104-7.

5. Singh B, Mc Mortensen NJ, Jewell DP, George B. Perianal Crohn's disease. Br J Surg 2004; 91: 801-14.

6. Glass RE, Ritchie JK, Lennard-Jones JE, Hawley PR, Todd IP. Internal fistulas in Crohn's disease. Dis Colon Rectum 1985; 28: 557-61.

7. Broe PJ, Bayless TM, Cameron JL. Crohn's disease: Are enteroenteral fistulas an indication for surgery? Surgery 1982; 91: 249-53.

8. Weissman RI, Orsay CP, Pearl RK, Abcarian H. The role of fistulography in fistula in anus. Dis Colon Rectum 1991; 34: 181-4.

9. Sandborn WJ, Fazio VW, Feagan BG, Hanauer SB. AGA technical review on perianal Crohn's disease. Gastroenterology 2003; 125: 1508-30.

10. Schratter-Sehn AU, Lochs H, Vogelsang H, Schurawitzki H, Herold C, Schratter M. Endoscopic ultrasonography versus computed tomography in the differential diagnosis of perianorectal complications in Crohn's disease. Endoscopy 1991; 25: 582-6.

11. Yousem DM, Frisman EK, Jones B. Crohn's disease, pelvirrectal and perianal finfings at CT. Radiology 1988; 167: 394-6.

12. Haggett PJ, Moore NR, Shearman JD, Travis SPL, Jewell DP, Mortensen NJ. Pelvic and perineanal complications of Crohn's disease: Assessment using magnetic resonance imaging. Gut 1995; 36: 407-10.

13. Lunniss PJ, Armstrong P, Barker PG, Reznek RH, Phillip RKS. Magnetic resonance imaging of anal fistulae. Lancet 1992; 390: 394-6.

14. Shajej M, Bongers H, Aicher H, Weihlich M, Starlinger M, Jenss H. Value of MR tomography in perineal Crohn's disease; A prospective study. Gastroenterology 1992; 102 (Supl. A): 697.

15. De la Portilla F, Alós R. Miscelanea. En: de la Portilla F, editor. Principios Prácticos de Ecografía anal y rectal. Madrid: Ed. Díaz de Santos; 2004. p. 107-10.

16. Van Outryre MJ, Pelckmans PA, Michielsen PP, Van Maercke YM. Value of transrectal ultrasonography in Crohn's disease. Gastroenterology 1991; 101: 1171-7.

17. Lew RJ, Ginsberg GG. The role of endoscopic ultrasound in inflammatory bowel disease. Gastrointest Endosc Clin N Am 2002; 12: 561-71.

18. Sloots CE, Felt-Bersma RJ, Poen AC, Cuesta MA, Meuwissen SG. Assessment and classification of fistula-in-ano in patients with Crohn's disease by hydrogen peroxide enhanced transanal ultrasound. Int J Colorectal Dis 2001; 16: 292-7.

19. Tio TL, Mulder JJ, Wijers OB, Sars PRA, Tytgat GNJ. Endosonography of perianal and pericolorectal fistula and/or abscess in Crohn's disease. Gastrointest Endosc 1990; 36: 331-4.

20. Van Bodegraven AA, Sloots CE, Felt-Bersma RJ, Meuwissen SG. Endosonographic evidence of persistence of Crohn's disease-associated fistulas after infliximab treatment, irrespective of clinical response. Dis Colon Rectum 2002; 45: 39-45.

21. Schwartz DA, Wiersema MJ, Dudiak KM, Fletcher JG, Clain JE, Tremaine WJ, et al. A comparison of endoscopic ultrasound, magnetic resonance imaging, and exam under anesthesia for evaluation of Crohn's perianal fistulas. Gastroenterology 2001; 121: 1064-72.

22. Wedemeyer J, Kirchhoff T, Sellge G, Bachmann O, Lotz J, Galanski $\mathrm{M}$, et al. Transcutaneous perianal sonography: A sensitive method for the detection of perianal inflammatory lesions in Crohn's disease. World J Gastroenterol 2004; 10: 2859-63.

23. Stewart LK, McGee J, Wilson SR. Transperineal and transvaginal sonography of perianal inflammatory disease. AJR Am J Roentgenol 2001; 177: 627-32. 